\title{
Comparison of demographic and clinical characteristics in distinguishing testicular torsion from torsion of the appendix testis
}

\section{Zlatan Zvizdic}

University Clinical Center Sarajevo

\section{Amila Aganovic}

Ingolstadt Hospital: Klinikum Ingolstadt GmbH

Emir Milisic

University Clinical Center Sarajevo

Asmir Jonuzi

University Clinical Center Sarajevo

Denisa Zvizdic

University Clinical Center Sarajevo

Semir Vranic ( $\nabla$ semir.vranic@gmail.com )

Qatar University https://orcid.org/0000-0001-9743-7265

\section{Research Article}

Keywords: Acute scrotum, testicular torsion, torsion of the appendix testis, children

Posted Date: May 24th, 2021

DOI: https://doi.org/10.21203/rs.3.rs-461129/v1

License: (9) (i) This work is licensed under a Creative Commons Attribution 4.0 International License. Read Full License 


\section{Abstract \\ Purpose}

The acute scrotum (AS) in the pediatric population is a medical emergency. The most common causes of AS include testicular torsion (TT) and torsion of the appendix testis (TAT). Their distinction may be clinically challenging. The purpose of our study was to compare demographic and clinical characteristics of the pediatric cases of TT and TAT and thus provide clinical evidence for distinguishing these two conditions.

\section{Methods}

We retrospectively analyzed all children $\leq 16$ years who underwent surgical exploration for AS. The patients were divided into Group 1 or TT and Group 2 or TAT groups.

\section{Results}

Ninety patients were included in the study ( 24 with TT and 66 with TAT). Patients with TT were significantly older than those with TAT $(p<0.001)$. The peak incidence of TT was in the age of 12-16 years $(p<0.001)$, whereas the peak of TAT was in the age group of $7-11$ years $(p<0.001)$. Scrotal pain was more prevalent in patients with TAT $(p=0.02)$, whereas systemic signs (nausea/vomiting and abdominal pain) affected more frequently the TT patients ( $p=0.003$ and $p<0.001$, respectively). The mean duration of symptoms was significantly longer in the TAT group than in the TT group $(p<0.001)$. Color-Doppler Ultrasound (CDUS) findings of absent or decreased testicular blood flow in the affected testis strongly favored the diagnosis of TT $(p<0.001)$.

\section{Conclusion}

Our data indicate that the older age, shorter duration of symptoms, systemic signs (nausea/vomiting and abdominal pain), and characteristics CDUS findings can help distinguish between the two most common acute scrotum causes.

\section{Introduction}

In childhood or adolescence, the acute scrotum (AS) is a medical emergency characterized by acute scrotal pain with or without swelling and erythema [1]. The most common pathologies encountered in the broad spectrum of pediatric AS are torsion of the appendix testis (TAT), testicular torsion (TT), and epididymo-orchitis (EO). The most important differential diagnosis for AS is TT, which accounts for up to $25 \%$ of acute scrotal disease in the pediatric population [2]. In contrast, the most frequently detected 
pathology during scrotal exploration is TAT, representing $54-71 \%$ of the operative diagnosis of AS [3-5]. TAT makes up to $95 \%$ of torsed appendices [6].

Clinical distinction between TT and TAT is frequently tricky but critical because timely assessment and intervention in TT cases can preserve the affected testicle $[7,8]$. Various studies have dealt with differentiating TT from TAT [9-11]. However, differential diagnosis of AS, particularly TT, remains challenging and shows a considerable risk of misdiagnosis [11].

The present study analyzed the pediatric cohort of TT and TAT and explored the impact of baseline demographic and clinical characteristics on differential causes of AS.

\section{Material And Methods}

We conducted a retrospective study using a cohort of pediatric patients presenting with AS who underwent scrotal exploration between 2011 and 2016. Data were obtained from the medical records. We divided the patients into two groups according to the operative findings: Group 1 or TT group and Group 2 or TAT group, and compared baseline demographic and clinical characteristics between them. Inclusion criteria for the study were confirmed diagnosis of TT or TAT and age below 16 years. Those with other causes of AS and those with incomplete or missing data were excluded from the study.

The following demographic and clinical characteristics were recorded: Age, laterality (right/left), presenting symptoms (scrotal pain, erythema of the scrotal skin, swelling, nausea/vomiting, abdominal pain, and fever), duration of symptoms, seasonality, history of scrotal trauma, and Color-Doppler Ultrasound (CDUS). Patients' age was categorized into five groups: $<1$ year, $1-3,4-6,7-11$, and 12-16 years.

All patients underwent testicular ultrasonography with CDUS before surgery. The access for surgical exploration of the testis in all cases was through the midline scrotal incision. TT was defined as a twisting of the spermatic cord and its contents with resultant ischemia due to compromised blood flow to the testicle. TAT was defined as twisting and ischemia of the testicular appendage located on the superior pole of the testicle between the testis and epididymis.

\section{Statistical analysis}

Mean and median were used to measure central tendency and standard deviation and range as dispersion measures for continuous variables. The values of categorical variables were presented as numbers or percentages. The Kolmogorov-Smirnov test tested the normality of data distribution for each of the variables. Chi-Square and Fisher's exact tests were used to explore the differences between the categorical variables. $P$-values $<0.05$ were considered significant. All statistical assays were performed using the Statistical Package for the Social Sciences (SPSS) IBM Version 26 (SPSS) (UNICOM Systems, Inc.). 


\section{Results}

The baseline demographic and clinical characteristics of the two pediatric cohorts are presented in Table 1.

Ninety-eight pediatric patients with AS were identified in the period 2011-2016. Eight patients were excluded from the study as they had other pathologies (e.g., EO, $n=4)$ or incomplete clinical histories $(n=$ 4). Thus, 90 patients with TT and TAT met the inclusion criteria and constituted the final cohort.

Twenty-four TT cases (26.6\%) (Group I) and 66 (73.4\%) TAT cases (Group 2) were seen during the study period. Patients with TT in this study were significantly older [ $13.5 \pm 2.6$ years (range, ten days -15.8 years)] than those with TAT $[9.5 \pm 2.8$ years (range $0.7-14.7$ years)] $(p<0.001)$.

Although TT and TAT affected the children across different ages, significant differences in both groups were observed. Thus, the peak incidence of TT was in the age of $12-16$ years (75\%), whereas the peak of TAT was in the age group of $7-11$ years $(57 \%)(p<0.001$ for both calculations).

There was no statistically significant difference between the two groups in laterality $(p=0.28)$. However, left-sided scrotal involvement was more common in TT cases $(66 \%)$, whereas there was no significant difference in affected sides in TAT cases. Interestingly, we found that right-sided TT increases in adolescent patients: Left-side TT involvement was recorded in 100\% of patients under 12 years. In comparison, the incidence on that side dropped to $55.6 \%$ in patients aged $\geq 12$.

Scrotal pain, erythema of the scrotal skin, and scrotal swelling were the most common clinical symptoms in both observed groups (Table 1). Interestingly, scrotal pain (without recorded accurate localization of tenderness and its intensity) was statistically more present in TAT patients $(p=0.02)$. In contrast, nausea/vomiting and abdominal pain occurred more frequently among the TT patients $(p=0.003$ and $p$ $<0.001$, respectively). Notably, fever and abdominal pain did not affect any TAT patients (Table 1).

The mean duration of symptoms for the entire cohort was 63.3 hours (range, 30 minutes to 480 hours) with a median of 48 hours. The mean duration of symptoms was significantly shorter in the TT group (42 hours, range, 1-336 hours) than in the TAT group (71 hours, range, 1-480 hours) $(p<0.001)$.

There was no significant difference in the seasons of onset between TT patients and those with TAT ( $p=$ 0.31). The lowest TT cases $(21 \%)$ were recorded during the winter, whereas the largest TAT cases $(28.7 \%)$ were recorded during the same season.

A vast majority of the cases ( $91.7 \%$ of TT and $83.3 \%$ of TAT cases) had a spontaneous torsion, whereas the remaining $8.3 \%$ of TT cases and $16.3 \%$ of TT cases were trauma-related. However, the difference was not statistically significant $(p=0.50)$.

Ultrasonographically, the two diseases presented strikingly different. Thus, twenty-three patients with TT (96\%) and only five patients with TAT (7.5\%) showed absent or decreased testicular blood flow in the 
affected testes, whereas 61 (92.5\%) patients with TAT and only 1 (4\%) patient with TT showed increased or normal testicular blood flow in the affected testes (Table 1). CDUS findings of absent or decreased testicular blood flow in the affected testes significantly correlated with TT's presence $(p<0.001)$. In contrast, CDUS findings of increased or normal blood flow had a significant correlation with the presence of TAT $(p<0.001)$.

\section{Discussion}

It is well documented that TAT is the most common cause of AS in children who underwent scrotal exploration [12]. Emergency scrotal exploration is the standard means of management, as no other investigation can confidently exclude TT from the differential diagnosis of AS [13]. Our results for the occurrence of TT and TAT are in line with the previous studies [5, 12-16]. Of pediatric patients with AS who underwent emergency surgery, TT is the cause of $17-72 \%$ of cases $[5,13,14,16]$. In our study, TT occurred in $\sim 27 \%$ of cases, whereas TAT affected $73 \%$ of the AS patients. Like other studies [11], the patients with TT were the eldest, and their presentation was the earliest compared with the TAT patients. Consistent with previous studies, our findings of 24 TT patients indicate that this condition occurs more frequently on the left side $[17,18]$. This could be anatomically related to the greater length of the left spermatic cord, which is more prone to twisting [19]. Data in the literature on the association between age and laterality of TT are scarce. Our finding that the occurrence of right-sided TT increases in adolescent patients is consistent with the study conducted by Mukendi et al. [18]. Further studies on a larger sample are necessary to determine the clinical significance of this association. A history of nausea/vomiting and abdominal pain, as markers of a systemic response to an ischemic event in the body secondary to celiac ganglion stimulation, strongly suggest TT. However, they are absent in more than two-thirds of patients. Similar results have been reported in other studies $[20,21]$. We believe that the higher frequency of scrotal pain in patients with TAT could be explained by the lack of registration of the exact localization of pain and the initial presentation of a larger number of patients with advanced local scrotal findings. Our previous study showed that the duration of symptoms is the most crucial predictor of testicular salvage following TT in children [22]. In the present study, the duration of symptoms was significantly different between the two groups. Like another study [9], our patients with TT had a significantly shorter time to presentation than patients with TAT. This could be explained by the more extensive symptoms caused by TT compared with TAT symptoms, leading to an earlier visit to the doctor. The seasonal influence on TT or TAT is contradictory in the current literature. While some studies have found a link between cold weather and TT and TAT [23, 24], other studies failed to provide this evidence [25]. Our study has not found a positive association between cold weather and TT. Although most TT and TAT cases develop spontaneously, the causes of TT and TT may be trauma-related (sports or physical activity) in $~ 5 \%$ of cases [26]. History of trauma was present in $8.3 \%$ of TT cases and $16.7 \%$ of TAT cases. Our study did not reveal a significant difference in the history of trauma between the examined groups. CDUS has substantially improved patients' clinical assessment with AS, determining TT's presence and the extent and reducing the unnecessary exploration rate $[27,28]$. On sonography, the torsed testis typically may be enlarged and appear hypoechoic, but sometimes it can appear normal, particularly in the first few hours 
[27]. In the evaluation of AS, CDUS has a sensitivity of $~ 64-100 \%$ and a specificity of $97-100 \%$, showing reduced or absent blood flow to the testis as a highly specific finding in the vast majority of the TT patients [29]. However, false-negative and false-positive Doppler evaluations in the diagnosis of TT have been reported in the literature. Our study's data further support the excellent clinical utility of CDUS in differentiating between the TT and TAT. There are several limitations to our study. First, it is a retrospective observational study, and second, the study comprises a smaller number of patients with TT. The present study also lacks some essential clinical data, such as a lack of precise localization of scrotal pain. In conclusion, distinguishing TT from other acute scrotal pathology, including TAT, is crucial for timely surgical intervention and preservation of testes affected by AS. Older age, nausea/vomiting, abdominal pain, shorter duration of symptoms, and CDUS findings of absent or decreased testicular blood flow in the affected testis can distinguish between TT and TAT.

\section{Declarations}

\section{Authors' contributions}

Zlatan Zvizdic: Conceptualization; Data Curation; Formal analysis; Methodology; Writing - original draft.

Amila Aganovic, Emir Milisic, Asmir Jonuzi, Denisa Zvizdic: Data curation; formal analysis, Validation.

Semir Vranic: Conceptualization; Data curation; Formal analysis; Supervision; Writing - review \& editing.

\section{Declaration of Competing Interest}

The authors declare no conflict of interest.

\section{Availability of data and material}

All the data are reported in the study.

\section{Code Availability}

Not applicable.

\section{Ethical approval}

All medical records were de-identified and anonymized for the current study. The study was approved by the local institutional review board (IRB) (Ethical Committee of the Clinical Center, University of Sarajevo, number: 0901-2-678/18).

\section{Consent to participate}

The IRB waived informed consent due to the retrospective nature of the study. 


\section{References}

1. Gatti JM, Murphy JP. Acute testicular disorders. Pediatr Rev. 2008;29(7):235-41. https://doi.org/10.1542/pir.29-7-235.

2. Lemini R, Guana R, Tommasoni N, Mussa A, Di Rosa G, Schleef J. Predictivity of Clinical Findings and Doppler Ultrasound in Pediatric Acute Scrotum. Urol J. 2016;13(4):2779-83. https://www.ncbi.nlm.nih.gov/pubmed/27576885.

3. Hart J, Pastore G, Jones M, Barker A, Khosa J, Samnakay N. Chronic orchalgia after surgical exploration for acute scrotal pain in children. J Pediatr Urol 2016;12(3):168 e1-6. https://doi.org/10.1016/j.jpurol.2015.11.014.

4. Lala S, Price N, Upadhyay V. Re-presentations and recurrent events following initial management of the acute paediatric scrotum: a 5-year review. ANZ J Surg. 2019;89(4):E117-E21. https://doi.org/10.1111/ans.13905.

5. Mushtaq I, Fung M, Glasson MJ. Retrospective review of paediatric patients with acute scrotum. ANZ J Surg 2003;73(1-2):55 - 8. https://doi.org/10.1046/j.1445-2197.2003.02612.x.

6. Vijayaraghavan SB. Sonographic differential diagnosis of acute scrotum: real-time whirlpool sign, a key sign of torsion. J Ultrasound Med. 2006;25(5):563-74. https://doi.org/10.7863/jum.2006.25.5.563.

7. Kumar V, Matai P, Prabhu SP, Sundeep PT. Testicular Loss in Children Due to Incorrect Early Diagnosis of Torsion. Clin Pediatr (Phila). 2020;59(4-5):436-8. https://doi.org/10.1177/0009922820903037.

8. Boettcher M, Bergholz R, Krebs TF, Wenke K, Aronson DC. Clinical predictors of testicular torsion in children. Urology. 2012;79(3):670-4. https://doi.org/10.1016/j.urology.2011.10.041.

9. Fujita N, Tambo M, Okegawa T, Higashihara E, Nutahara K. Distinguishing testicular torsion from torsion of the appendix testis by clinical features and signs in patients with acute scrotum. Res Rep Urol. 2017;9:169-74. https://doi.org/10.2147/RRU.S140361.

10. Tanaka K, Ogasawara Y, Nikai K, Yamada S, Fujiwara K, Okazaki T. Acute scrotum and testicular torsion in children: a retrospective study in a single institution. J Pediatr Urol. 2020;16(1):55-60. https://doi.org/10.1016/j.jpurol.2019.11.007.

11. Ciftci AO, Senocak ME, Tanyel FC, Buyukpamukcu N. Clinical predictors for differential diagnosis of acute scrotum. Eur J Pediatr Surg. 2004;14(5):333-8. https://doi.org/10.1055/s-2004-821210.

12. Murphy FL, Fletcher L, Pease P. Early scrotal exploration in all cases is the investigation and intervention of choice in the acute paediatric scrotum. Pediatr Surg Int. 2006;22(5):413-6. https://doi.org/10.1007/s00383-006-1681-0.

13. Cavusoglu YH, Karaman A, Karaman I, Erdogan D, Aslan MK, Varlikli O, et al. Acute scrotum - etiology and management. Indian J Pediatr. 2005;72(3):201-3. https://www.ncbi.nlm.nih.gov/pubmed/15812112. 
14. Van Glabeke E, Khairouni A, Larroquet M, Audry G, Gruner M. Acute scrotal pain in children: results of 543 surgical explorations. Pediatr Surg Int. 1999;15(5-6):353-7. https://doi.org/10.1007/s003830050598.

15. McAndrew HF, Pemberton R, Kikiros CS, Gollow I. The incidence and investigation of acute scrotal problems in children. Pediatr Surg Int. 2002;18(5-6):435-7. https://doi.org/10.1007/s00383-0020806-3.

16. Yang C, Song B, Tan J, Liu X, Wei GH. Testicular torsion in children: a 20-year retrospective study in a single institution. ScientificWorldJournal. 2011;11:362-8. https://doi.org/10.1100/tsw.2011.39.

17. Marulaiah M, Gilhotra A, Moore L, Boucaut H, Goh DW. Testicular and paratesticular pathology in children: a 12-year histopathological review. World J Surg. 2010;34(5):969-74. https://doi.org/10.1007/s00268-010-0459-7.

18. Mukendi AMKD, Hafejee M. Characteristics and management of testicular torsion in patients admitted to the Urology Department at Chris Hani Baragwanath Academic Hospital. Afr J Urol. 2020;26:34.

19. Williamson RC. Torsion of the testis and allied conditions. Br J Surg. 1976;63(6):465-76. https://doi.org/10.1002/bjs.1800630618.

20. Hegarty PK, Walsh E, Corcoran MO. Exploration of the acute scrotum: a retrospective analysis of 100 consecutive cases. Ir J Med Sci. 2001;170(3):181-2. https://doi.org/10.1007/BF03173885.

21. Srinivasan A, Cinman N, Feber KM, Gitlin J, Palmer LS. History and physical examination findings predictive of testicular torsion: an attempt to promote clinical diagnosis by house staff. J Pediatr Urol. 2011;7(4):470-4. https://doi.org/10.1016/j.jpurol.2010.12.010.

22. Zvizdic Z, Aganovic A, Milisic E, Jonuzi A, Zvizdic D, Vranic S. Duration of symptoms is the only predictor of testicular salvage following testicular torsion in children: A case-control study. Am J Emerg Med. 2020. https://doi.org/10.1016/j.ajem.2020.11.023.

23. Lyronis ID, Ploumis N, Vlahakis I, Charissis G. Acute scrotum -etiology, clinical presentation and seasonal variation. Indian J Pediatr. 2009;76(4):407-10. https://doi.org/10.1007/s12098-009-00082.

24. Molokwu CN, Ndoumbe JK, Goodman CM. Cold weather increases the risk of scrotal torsion events: results of an ecological study of acute scrotal pain in Scotland over 25 years. Sci Rep. 2020;10(1):17958. https://doi.org/10.1038/s41598-020-74878-0.

25. Cost NG, Bush NC, Barber TD, Huang R, Baker LA. Pediatric testicular torsion: demographics of national orchiopexy versus orchiectomy rates. J Urol. 2011;185(6 Suppl):2459-63. https://doi.org/10.1016/j.juro.2011.01.016.

26. Ringdahl E, Teague L. Testicular torsion. Am Fam Physician. 2006;74(10):1739-43. https://www.ncbi.nlm.nih.gov/pubmed/17137004.

27. Sung EK, Setty BN, Castro-Aragon I. Sonography of the pediatric scrotum: emphasis on the Tstorsion, trauma, and tumors. AJR Am J Roentgenol. 2012;198(5):996-1003. https://doi.org/10.2214/AJR.11.8034. 
28. Lam WW, Yap TL, Jacobsen AS, Teo HJ. Colour Doppler ultrasonography replacing surgical exploration for acute scrotum: myth or reality? Pediatr Radiol. 2005;35(6):597-600. https://doi.org/10.1007/s00247-005-1411-0.

29. Chmelnik M, Schenk JP, Hinz U, Holland-Cunz S, Gunther P. Testicular torsion: sonomorphological appearance as a predictor for testicular viability and outcome in neonates and children. Pediatr Surg Int. 2010;26(3):281-6. https://doi.org/10.1007/s00383-009-2534-4.

\section{Tables}




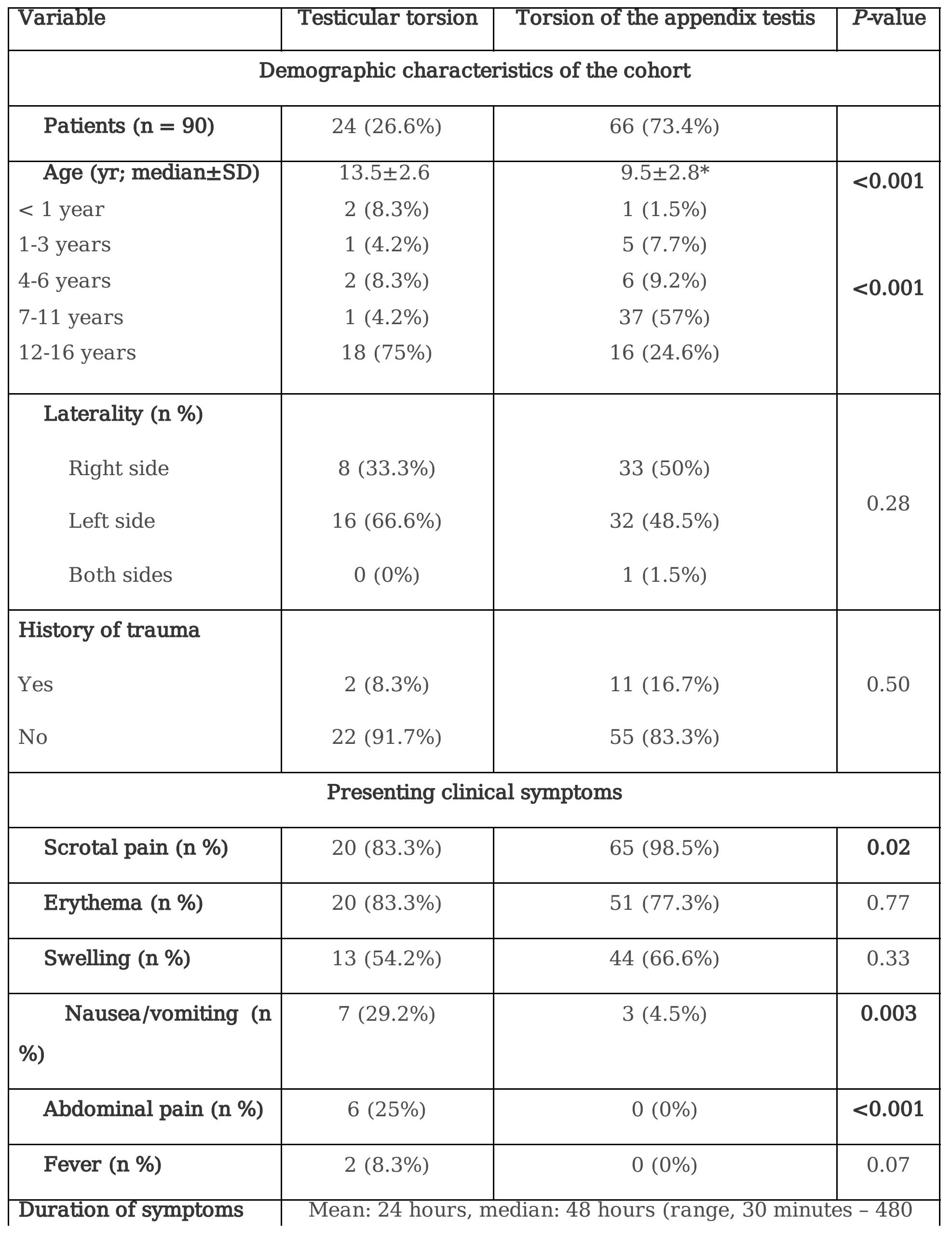




\begin{tabular}{|c|c|c|c|}
\hline & & urs) & \\
\hline$\leq 6$ hours & $9(37.5 \%)$ & 7 (10.6\%) & \\
\hline 6-12 hours & $0(0 \%)$ & $4(6 \%)$ & \\
\hline 12-24 hours & 7 (29.2\%) & $5(7.5 \%)$ & $<0.001$ \\
\hline$>24$ hours & $8(33.3 \%)$ & $50(75.7 \%)$ & \\
\hline Season & & & \\
\hline Spring & $4(16.6 \%)$ & $18(27.2 \%)$ & \\
\hline Summer & $8(33.3 \%)$ & $11(16.7 \%)$ & 0.31 \\
\hline Autumn & 7 (29.2\%) & $18(27.2 \%)$ & \\
\hline Winter & $5(21 \%)$ & $19(28.7 \%)$ & \\
\hline & lor Doppler & lings & \\
\hline $\begin{array}{l}\text { Absent/decreased } \\
\text { flow }\end{array}$ & $\begin{array}{c}23(96 \%) \\
1(4 \%)\end{array}$ & $\begin{array}{c}5(7.5 \%) \\
61(92.5 \%)\end{array}$ & $<0.001$ \\
\hline $\begin{array}{l}\text { Increased/normal } \\
\text { flow }\end{array}$ & & & \\
\hline
\end{tabular}

Only significant variable values are bolded.

*Age is missing for one patient in this category.

SD, Standard deviation

Table 1. Baseline demographic, clinical characteristics and ultrasonography findings of patients with testicular torsion and torsion of the appendix testis.

\section{List Of Abbreviations}

AS

Acute scrotum

CDUS

Color-Doppler Ultrasound

EO

Epididymo-orchitis 
TAT

Torsion of the appendix testis

TT

Testicular torsion

Page 12/12 